\title{
The involvement of exosomes in the diagnosis and treatment of pancreatic cancer
}

\author{
Abakundana Nsenga Ariston Gabriel ${ }^{1,2+}$, Fang Wang ${ }^{3+}$, Qinlian Jiao ${ }^{1,4}$, Umwali Yvette ${ }^{5,2}$, Xuemei Yang ${ }^{1}$, \\ Samed Ahmed Al-Ameri ${ }^{1,2}$, Lutao Du ${ }^{1 *}$, Yun-shan Wang ${ }^{1 *}$ and Chuanxin Wang ${ }^{1 *}$ (D)
}

\begin{abstract}
At the moment, pancreatic cancer is among the deadliest gastrointestinal diseases, and pancreatic cancer growth is a complex biological process that is based on different kinds of genes. Exosomes are extracellular vesicles containing microRNAs (miRNAs), messenger RNA (mRNA), and proteins, they act as the most prominent mediator of intercellular communication, and they regulate, instruct, and re-educate their surrounding microenvironment and target specific organs. Due to accumulative evidence proved that exosomes are involved in metastasis, cell proliferation, EMT, angiogenesis, and TME of pancreatic cancer, exosomes are crucial potential candidates to detect pancreatic cancer early. This review aims to convey the current understanding of the main functions employed by exosomes in early diagnosis and treatment of pancreatic cancer.
\end{abstract}

Keywords: Exosomes, Pancreatic cancer, Biomarker, Treatment

\section{Introduction}

At the moment, pancreatic cancer is among the most deadly gastrointestinal cancerous diseases [1]. Pancreatic cancer symptoms are atypical, the development of the illness is too fast, and there are no sensitive early diagnostic biomarkers or proper clinical treatment [2]. Pancreatic cancer growth is a complex biological process that is based on different genes that are mutated [3]. PC is also a malignant disorder with poor prognosis, listed globally for the fourth fatal malignancy [4]. Statistically, in the United States, there are nearly 45,000 reported new cases recorded yearly, and 5-year survival rates over are less than 5\% [5]. Even though researches have

\footnotetext{
* Correspondence: lutaodu@sdu.edu.cn; wangyunshan135@126.com; cxwang@sdu.edu.cn

${ }^{\dagger}$ Abakundana Nsenga Ariston Gabriel and Fang Wang contributed equally to this work.

'Department of Clinical Laboratory, The Second Hospital, Cheeloo College of Medicine, Shandong University, Jinan, Shandong 250033, People's Republic of China

Full list of author information is available at the end of the article
}

achieved considerable advances in several aspects, especially genes, proteins, and cells, most of the PC malignant biological processes need to be explained at a very advanced level [6]. Many pancreatic cancer patients fail to present influential signs until they enter the stage of disease progression. Various studies reported some significant risk factors that may cause the development of pancreatic cancer. Some of those risk factors include smoking [7], family history of chronic pancreatitis [8], advancing age [9], male sex [10], diabetes mellitus [11], obesity [12], occupational exposures, African-American ethnic origin [13], a high-fat diet, diets high in meat and low in vegetables and folate [14], and possibly Helicobacter pylori infection [15]. Compared to many other cancer types, pancreatic cancer is remarkably caused by 4 essential genes that are mutated at a high number of patients suffering from PC. The most altered gene within pancreatic ductal adenocarcinoma consists of K-ras the proto-oncogene, which is usually mutationally activated above $90 \%$ cases [16]. Besides, tumor suppressors such 
as CDKN2A [17], p53 [18], and DPC4/SMAD4 [19] are also altered in above $95 \%$, between 50 and 75 , and 55\% of cases, respectively [20]. Exosomes are extracellular vesicles containing microRNAs (miRNAs), messenger RNA (mRNA), and proteins. Accumulative pieces of information proved that exosomes are potential candidates for early detection and diagnosis of pancreatic cancer [21]. Currently, various studies showed that increased or decreased expression of exosomes play an important role in different kinds of cancer, including pancreatic cancer [22]. For instance, exosomes are stimulating factors for the initiation and the development of pancreatic cancer, and this shows the ability of exosomes to be used as diagnostic biomarkers of pancreatic cancer [22].

Moreover, it has also been reported that there is a vast difference between the expression level of tumor-derived serum exosomes between pancreatic cancer patients and non-pancreatic cancer patients [23]. The conditions as mentioned above are due to the fact of that during carcinogenesis, pancreatic cancer patients secrete high amounts of circulating exosomes [24], and these secreted circulating exosomes are significantly detectable in body fluids, this also made researchers consider exosomes as potential diagnostic tools for early detection of pancreatic cancer [25]. Besides, recent research demonstrated that exosomes could directly and specifically target the oncogenic KRAS, which is also an essential gene in the development of pancreatic cancer, this made exosomes to be the best novel therapeutic candidates for pancreatic cancer [26]. In general, pancreatic cancer lacks different early diagnostic biomarkers and molecular target treatment that can significantly help in the battle of reducing pancreatic cancer fatalities around the world. In this review, we focus on the recent advances in our understanding of the main functions of exosomes in pancreatic cancer early diagnosis and treatment.

\section{Exosome main components}

Exosomes are extracellular vesicles which are often formed and produced by several cells; their size varies around 30 to $100 \mathrm{~nm}$ in diameter, and they have bilayer lipid [27]. As components, exosomes are composed of proteins, DNA, mRNA, miRNA, lipids, and non-coding RNA [28], all of the elements mentioned above are portrayed in Fig. 1a. One of the main functions of exosomes is to transfer nucleic acids and proteins into various recipient cells, and this facilitates both the transport of essential substances and the communications between cells [29].

Exosomes are composed of a range of proteins, such as heat-shock proteins (Hsp70, Hsp90) [30], tetraspanins (CD9, CD81), proteins associated with ESCRT (Alix, Tsg101), cytoskeletal proteins (actin, tubulin), and GTPases [31]. These proteins participate in the production sorting and secretion of exosomes [32], and they are also involved in antigen presentation, membrane microdomain structure, cytoskeleton, and endosomal network [33].
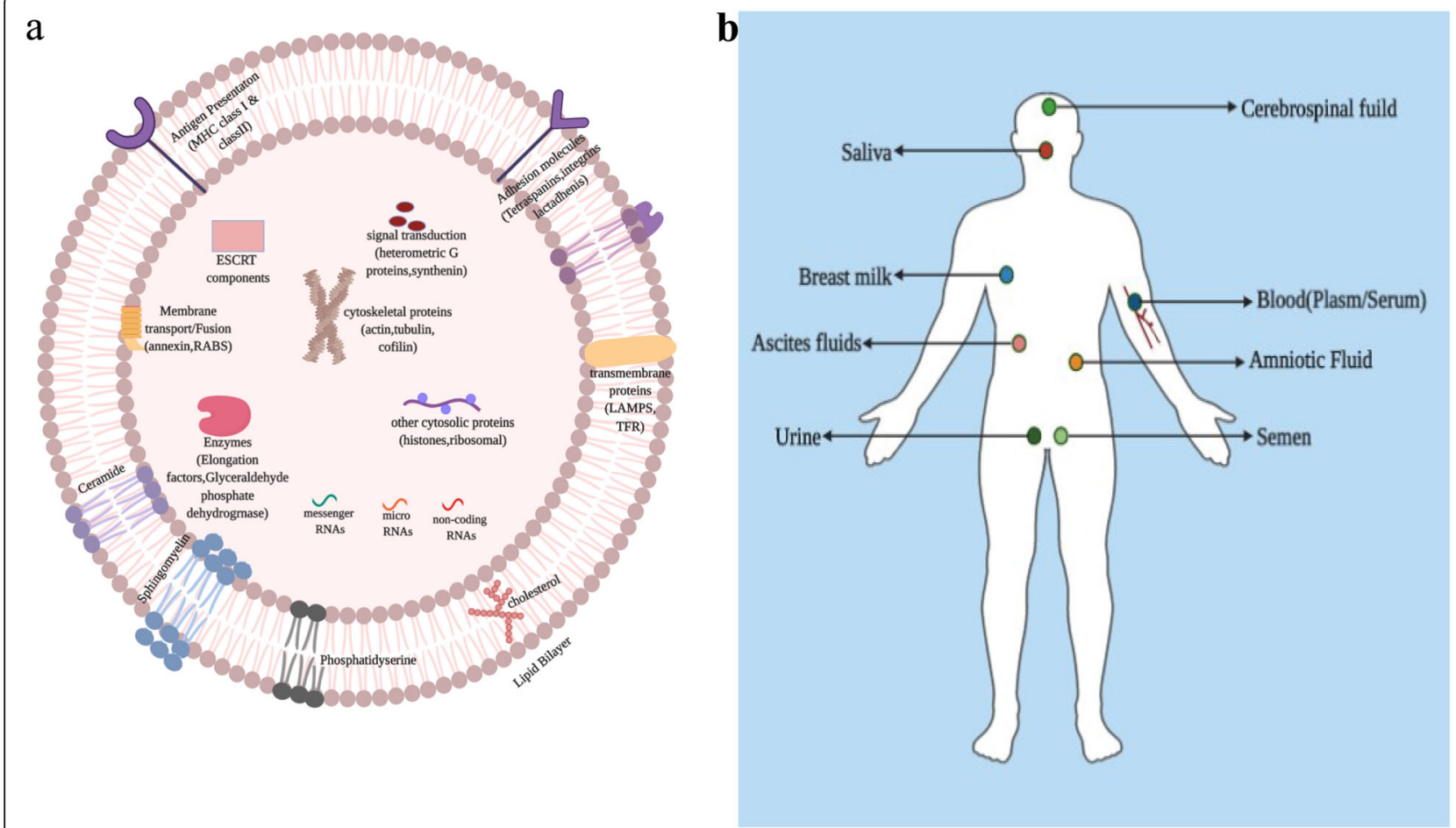

Fig. 1 a: Shows the essential components of exosomes. b: Presents different boy fluids where exosomes are found 
Exosomes also comprise nucleic acids, such as DNA, mRNAs, miRNAs, and long non-RNAs (lncRNAs) [34]. Among these, miRNAs are indeed known molecules that are involved in gene regulation after genetic transcription events [35]. Growing evidence has shown that exosomal miRNAs are strongly linked to several cancers, including pancreatic cancer [36]. Different studies focused on exosomal microRNA because some exosomal contents are the same as that of the original tumor [37]. As it is presented on Fig. 1b, exosomes can be detected in different kinds of body fluids such as cerebrospinal fluid, saliva, plasma/serum, breast milk, ascites fluids, amniotic fluid urine and semen, which made exosomal microRNA to be considered as a candidate for diagnosing various cancers, including pancreatic cancer [38]. Additional exosomal components like cholesterols, ceramide, sphingomyelins are also crucially involved in the initial production of exosomes [39].

\section{Leading significant clinically relevant roles of exosomes in pancreatic cancer}

Exosomes play essential roles in pancreatic cancer cell proliferation, metastasis, EMT, and angiogenesis

Exosomes have been shown to regulate both the development and progression of pancreatic cancer, which means that exosomes are involved in EMT, Metastasis, and cell proliferation Fig. 2 [40]. For example, Li Z et al. reported that tumor-generated exosomes miR-222 induced the invasion and proliferation of nearby tumor cells, and these outcomes are achieved by regulating and re-localizing P27 [41]. Botla et al. demonstrated that downregulating microRNA-192 expression increased in the progression of pancreatic cancer [42]. Besides another study conducted by $\mathrm{Y} . \mathrm{Fu}$ and his colleagues indicated that the decreased expression of exosomal miR-98-5p promotes metastasis and cell proliferation of pancreatic cancer by downregulating MAP 4 K4. This exosomal microRNA also suppressed the MAPK/ERK pathway, which is essential in tumor formation [43]. Besides, Wang $S$ et al. reported that exosomal miR-182 increased both cell proliferation and migration by targeting $\beta-\operatorname{TrCP} 2$, which plays a critical role in regulating cell cycle checkpoints. Also, they proved that exosomal miR-182 also plays a significant role in pancreatic cancer progression [44]. Metastasis is essential in the progress of different types of cancers, and various studies have reported that exosomes are currently involved in pancreatic cancer metastasis [45]. It has been reported that exosomal miR-301a-3p mediated M2 macrophage polarization via PTEN/PI3K $\gamma$, and in return, this considerably promoted PC metastasis [46].

Interestingly, another study also reported that miR-21 expression in PDAC TAFs is very active in promoting both invasion and metastasis in pancreatic cancer [47]. Pancreatic cancer EMT is another critical, momentous event in pancreatic cancer development, and it has been found that it is possible to modulate EMT by using exosomes. For instance, miR-429, together with the low expression of miR-141, decreased pancreatic cancer development, metastatic behaviours, and it has also enhanced the expression rate of the primary regulators of EMT in pancreatic cancer [48]. A recent study by $\mathrm{Hu} \mathrm{J}$ et al. reported that miR-361-3p regulated ERK1/2-induced EMT in pancreatic cancer by facilitating DUSP2 mRNA degradation [49]. Angiogenesis, which is the formation of the new blood vessels that are necessary to transport oxygen and other substances needed to grow or the spreading

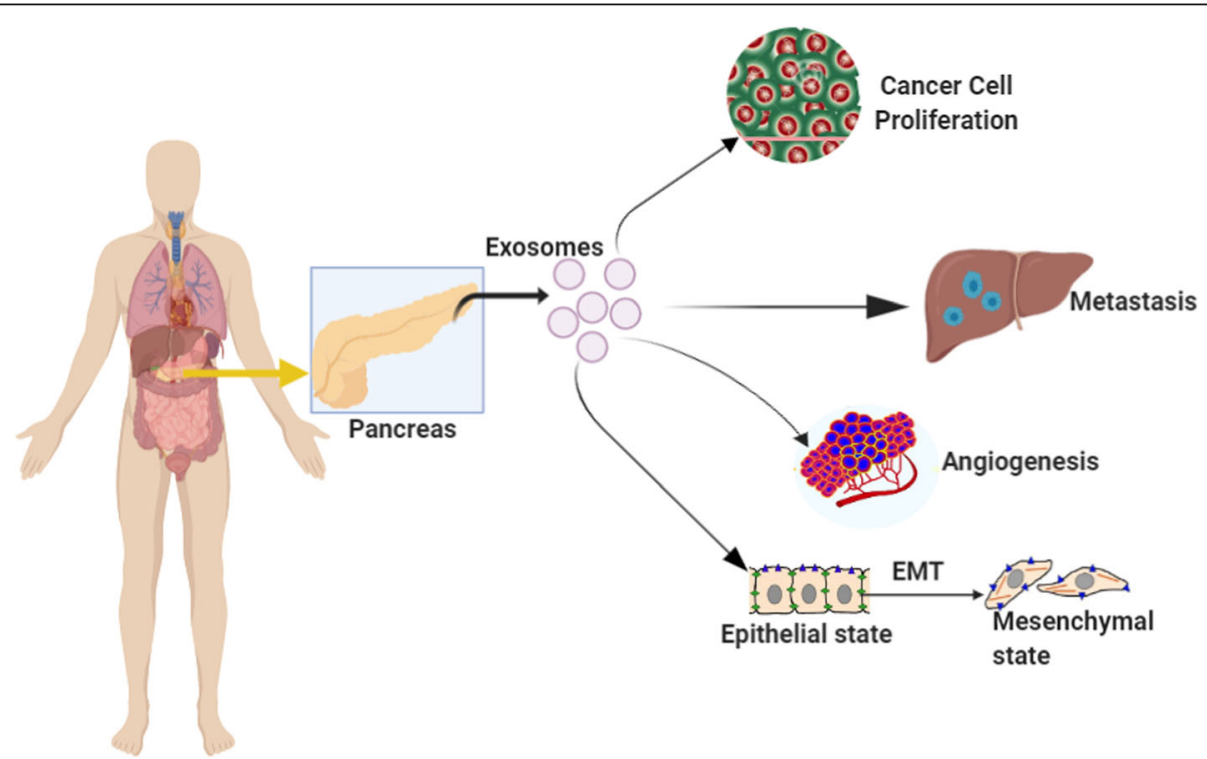

Fig. 2 Highlights the roles of exosomes in pancreatic cancer progression that includes cell proliferation, metastasis, angiogenesis, and EMT 
of the disease, angiogenesis is an essential event in different types of cancer, including pancreatic cancer [50]. Besides, accumulating shreds of evidence proved that exosomes play an essential role in pancreatic cancer angiogenesis [51]. Shang et al. reported that PC cellderived exosomal microRNA-27a significantly stimulated the angiogenesis of HMVEC in pancreatic cancer through BTG2 [52]. In conclusion, exosomes affect pancreatic cancer progression by regulating essential features such as angiogenesis, EMT, cell proliferation, and metastasis.

\section{Exosomes are promising tools to be used as pancreatic cancer biomarkers}

A cancer biomarker corresponds to a compound or process that shows the existence of cancer in the body [53]. A biomarker can be a substance naturally produced by a tumor or the body's unique reaction to the presence of disease [54]. One of the studies carried out on cancerrelated exosomes reported that cancer cells release lots of exosomes compared to non-cancerous cells. It has also been reported that cancer exosomes are crucially released into cancer microenvironment and circulatory system [55]. These results prove that exosome's components, which include miRNAs, are considered as a promising screening tool, and they can be used to strengthen the responsiveness and reliability of early pancreatic cancer detection [56]. Xu Y-F et al. reported that miR-196a and miR-1246 were highly expressed in exosomes derived from pancreatic cancer. These two miRNAs were found to be slightly elevated in plasma exosome specimens from patients who had localized PC juxtaposed to patients who had not PC [57]. Besides, Goto et al. also reported that exosomal miR-191, exosomal miR-21, and exosomal miR-451a were substantially increased in patients with PC and IPMN which was not the case to the patients who did not have PC [58]. Abue et al. also noted that plasma exosomes miRNA-483-3p expression was higher in pancreatic cancer patients compared with IPMN patients [59]. These findings, as mentioned above, make exosomal miRNAs a sensitive tool for early diagnosis of pancreatic cancer and an essential biomarker for distinguishing pancreatic cancer from IPMN. Furthermore, it has also been reported that miRNA-16a and miRNA-196a, together with CA19-9 [60], provided a positive outcome towards the identification of stage I of PC [61], suggesting that these exosomal microRNAs can also be used as PC peripheral biomarkers [62]. Also, in Kawamura's study, miR-4525, miR-451a, and miR-21 derived from portal vein have been proved possible biomarkers to determine the likelihood of recurrence and poor survival in patients with pancreatic cancer [63]. Furthermore, CKAP4, a DKK1 receptor, and secreted by exosomes, was also found to be a potential biomarker for pancreatic cancer [64]. Thus far, researchers did not stop exploring the role of exosomes as biomarkers for pancreatic cancer. By doing so, they found that exosomes extracted from pancreatic juice can catch a defined range of pathological biomarkers to help identify pancreatic cancer [65]. Machida et al. also reported that miR-1246 and miR-4644, which are freely available in saliva, could be considered as potential biomarkers for pancreaticobiliary tract cancer [66]. The studies mentioned above, which focused on the identification of the role of exosomal miRNA in the diagnosis of PDAC, providing evidence for the routine application of specific exosome components in the early detection of pancreatic cancer and additional information are presented in Table 1.

\section{Exosomes are essential in pancreatic cancer treatment}

Various studies highlighted that exosomes play a significant role in the treatment of pancreatic cancer by significantly reducing the progression and the aggressiveness of pancreatic cancer [73]. All points of view mentioned above are possible just because of exosomes' ability to carry and deliver different kinds of substances that target whether cancerous cells or genes involved in pancreatic cancer development [74]. For example, one of the studies showed that, after the priming of both MSCs and Paclitaxel, considerably stopped the proliferation of CFPAC-1 pancreatic cell lines by releasing paclitaxelhaving exosomes into a well-controlled cell culture medium [75]. It was also found that exosomes transfer Curcumin in pancreatic cancer cells to encourage in vitro cytotoxicity [23]. Besides, to deal with gemcitabine resistance in pancreatic cancer, Aspe JR et al. used exosomes to deliver survivin T34A to pancreatic cancer cell line (MiaPaCa-2) which in turn restored gemcitabine sensitivity in pancreatic cancer cell [76]. Using clinical trials, clinicians can determine whether new treatments are safe and effective in treating different diseases, including pancreatic cancer. Although there are not many clinical trials performed on using exosomes as drug carriers, currently, there is one clinical trial that is in its Phase I (NCT03608631). This clinical trial is using exosomes derived from mesenchymal stem cells to deliver small interference RNA that targets KrasG12D mutations in patients with metastatic pancreatic adenocarcinoma.

In cancer treatment, stopping cancer development is essential, basing on that various studies have carried out to verify whether exosomes can be used to prevent pancreatic cancer progression. For example, a recent study reported that exosomal miR-7 blocked pancreatic cancer events such as growth, migration, and invasion. Also, they noted that the overexpression of miR-7 inhibited tumor development in mice by directly targeting MAP 3 K9 [77]. Another study which had the aim of determining the role of DLC1 and microRNA-195 in pancreatic 
cancer, during their research, firstly, they noted that overexpression of miRNA-195 could stop proliferation, migration, and invasion of pancreatic cancer cells. Secondly, they also found that exosomal MicroRNA-195 suppressed PC development by targeting DCL1 [78]. It is also known that inhibiting some genes in combination with some exosomal microRNAs can help to inhibit cancer progression in different cancer types, including pancreatic cancer. An oncogene in pancreatic cancer known as TUG1 put together miRNA-299-3p brought a significant approach in treating pancreatic cancer [79]. The inhibition of the two significantly suppressed the Notch 1 pathway, and this could stop pancreatic cancer advancement [80]. Making some biological modifications on exosomes can also be a useful tool to produce new therapeutic novels to fight against pancreatic cancer. A study aimed at determining the curative abilities of miR16a reported that this exosomal microRNA could inhibit some essential genes involved in cell cycle arrest and cell proliferation [67]. It has been reported that miR-15a makes PC resistant to gemcitabine, to overcome this situation, they modified the exosomal micro RNA in question to 5-FU-miR-15a, which stopped PC cell proliferation. The combination significantly suppressed pancreatic cancer lung metastatic development [81]. Pancreatic cancer is one of a malignant disease that resists to some of the available chemotherapies, as the battle continues to eliminate this burden, the researchers found that exosomes may be excellent tools to prevent this problem, for example, it has been reported that microRNA-410-3p significantly reduced the PC cancer resistance to gemcitabine by inhibiting HMGB1mediated autophagy this made the exosomes to be considered as good candidates to be used in treating pancreatic cancer [82].

Pancreatic cancer is a cancerous disease which initiation is based on different gene mutations, such as TP53, Kras, CDKN2A [83]. Among all of those genes which are mutationally activated in PC, Kras is the most mutated gene in pancreatic cancer [84], and this made the researchers start to think that maybe targeting Kras gene pathways using exosomes could help in the treatment of pancreatic cancer. A recent study reported that an exosome that was extracted from normal fibroblast-

Table 1 Available exosomes involved in pancreatic cancer diagnosis

\begin{tabular}{|c|c|c|c|c|}
\hline $\begin{array}{l}\text { Type of } \\
\text { cancer }\end{array}$ & Used samples during the studies & Exosomes & $\begin{array}{l}\text { Application in } \\
\text { pancreatic } \\
\text { cancer }\end{array}$ & References \\
\hline \multirow[t]{13}{*}{$\begin{array}{l}\text { Pancreatic } \\
\text { cancer }\end{array}$} & $\begin{array}{l}\text { Exosomes were collected from the conditioned media of pancreatic } \\
\text { cancer cell lines and plasma samples of localized pancreatic cancer } \\
\text { patients (Stage I-IIA) healthy subjects. }\end{array}$ & miR-196a and miR-1246 & Diagnosis & {$[57]$} \\
\hline & $\begin{array}{l}\text { The exosomes were collected from patients with pancreatic cancer, } \\
\text { and patients without neoplasms (controls). }\end{array}$ & miR-191, miR-21, miR-451a & Diagnosis & {$[58]$} \\
\hline & $\begin{array}{l}\text { Plasma RNAs were extracted from pancreatic cancer patients, } \\
\text { chronic pancreatitis patients, and healthy controls. }\end{array}$ & $\begin{array}{l}\text { miRNA-16a and miRNA-196a, to- } \\
\text { gether with CA19-9 }\end{array}$ & Diagnosis & [62] \\
\hline & $\begin{array}{l}\text { The plasma samples were obtained from pancreatic ductal } \\
\text { adenocarcinoma (PDAC), intraductal papillary mucinous neoplasm } \\
\text { (IPMN) patients, and healthy controls. }\end{array}$ & miRNA-483-3p & Diagnosis & {$[59]$} \\
\hline & Saliva from pancreatobiliary tract cancer patients, healthy donors. & miR-1246 and miR-4644 & Diagnosis & {$[66]$} \\
\hline & $\begin{array}{l}\text { Portal vein blood and peripheral blood collected from PDAC patients } \\
\text { during curative pancreatectomy. }\end{array}$ & miR-4525, miR-451a, and miR-21 & Diagnosis & [63] \\
\hline & $\begin{array}{l}\text { The plasma of patients with primary pancreatic ductal } \\
\text { adenocarcinoma and plasma from healthy controls. }\end{array}$ & miR-155, miR196a & Diagnosis & {$[67]$} \\
\hline & $\begin{array}{l}\text { Serum from pancreatic cancer, chronic pancreatitis, and benign } \\
\text { pancreatic tumors patients, also they used serum from non- } \\
\text { pancreatic cancer. }\end{array}$ & $\begin{array}{l}\text { miR-1246, miR-4644, miR-3976, miR- } \\
4306 \text { and CD44v6, Tspan8, EpCAM, } \\
\text { MET, CD104 }\end{array}$ & Diagnosis & {$[24]$} \\
\hline & $\begin{array}{l}\text { The peripheral blood plasma of patients with PC and healthy } \\
\text { controls. }\end{array}$ & exmiR-21 & Diagnosis & [68] \\
\hline & $\begin{array}{l}\text { Serum, benign pancreatic tumors, ampullary carcinomas, chronic } \\
\text { pancreatitis, healthy donors. }\end{array}$ & $\operatorname{miR}-17-5 p$ & Diagnosis & [69] \\
\hline & $\begin{array}{l}\text { The plasma of pancreatic cancer, chronic pancreatitis patients, and } \\
\text { healthy controls. }\end{array}$ & miR-10b & Diagnosis & {$[70]$} \\
\hline & $\begin{array}{l}\text { The exosomes have been extracted from media that contained the } \\
\text { PANC1 cell line. }\end{array}$ & miR-550 & Diagnosis & {$[71]$} \\
\hline & $\begin{array}{l}\text { The exosomes were collected from the blood of pancreatic cancer, } \\
\text { chronic pancreatitis patients, normal donors. }\end{array}$ & $\begin{array}{l}\text { microRNA-10b, (miR-10b), miR-21, } \\
\text { miR-30c, and miR-181a and low } \\
\text { miR-let7a }\end{array}$ & Diagnosis & {$[72]$} \\
\hline
\end{tabular}


like mesenchymal and modified to bear siRNA targeting $\mathrm{Kras}^{\mathrm{G} 12 \mathrm{D}}$ was able to stop pancreatic cancer progression in different GEMMs and greatly improved these mouse models overall survival rates [85]. Basing on the facts mentioned above, it is clear that exosomes significantly play an essential role in treating pancreatic cancer.

\section{The involvement of exosomes in pancreatic cancer TME}

The tumor volume contains not just highly diverse cancerous cells groups; it also includes several essential and infiltrating host cells, secreted factors, and extracellular matrix proteins, generally referred to as the tumor microenvironment [86]. It is widely known that the tumor microenvironment is made up of macrophages, dendritic cells, $\mathrm{T}$ cells, endothelial cells and fibroblasts, proteases, cytokines, ECM play a significant role in tumor evolution and metastasis in different types of cancer especially in pancreatic cancer [87]. Growing pieces of evidence have demonstrated that exosomes are strongly connected to the tumor microenvironment [88]. Basing on these facts, researchers continued to explore more about the role of exosomes in the pancreatic cancer CAFs, which are essential components of the TME. It has been reported that some chemotherapies induce CAFs to start to release more exosomes, which in turn promote pancreatic cancer cell proliferation and drug resistance [89]. Exosomes also play a role as cell transformation initiator in human pancreatic cancer; a recent study reported that pancreatic cancer cell exosomes were involved in malignant cell transformation of $\mathrm{NIH} /$ 3 T3 cells, contrarily, this was impossible on exosomes from healthy pancreatic cells or primary fibroblast cells [90]. Macrophages-delivered exosomes are one of the pancreatic cancers TME components, and they are said to be involved in different PC essential events. Yin $\mathrm{Z}$ et al. showed that macrophage-derived exosomal miR501-3p suppresses the TGFBR3 gene and promotes the growth of PC by triggering the TGF- $\beta$ signaling pathway [91]. As mentioned above, it is quite clear that exosomes play essential roles in pancreatic cancer TME.

\section{Exosomes are essential tools to monitor response to therapy in pancreatic cancer}

Currently, different therapies are used to treat pancreatic cancer, and it is necessary to monitor or track the therapies' responses. One of the most common biomarkers is CA-19-9, has been used for so long to monitor the therapeutic responses in pancreatic cancer [92].

As mentioned earlier, exosomes play different roles in pancreatic cancer events like metastasis, cell proliferation, angiogenesis, and treatment of pancreatic cancer. Besides, exosomes are also believed to play a significant role in monitoring response to therapy. For example, one study tested cell surface proteoglycan, glypican-1 (GPC1) on serum exosomes in patients harbouring pancreatic cancer at both pre-and postoperative levels. The results highlighted a substantial decrease following surgical resection, suggesting that glypican-1 plus exosomes that may function as a noninvasive biomarker and a possible tracking tool for the identification of therapy response [93]. It has also been found that exosomal forms of the EGFR released from pancreatic cancer cells can also be the right candidate to track therapy response [94]. Another study which was done on plasma exosomes reported that increased rates of miR-221 in the blood found three weeks after initiation of treatment with lapatinib and capecitabine have been related to drug resistance, this made miR-221 be a right candidate for monitoring these two therapies response in pancreatic cancer treatment [95]. Also, Miyamae $\mathrm{M}$ et al. also noted that the high expression of miR-744 might be a useful tool to monitor chemoresistance in pancreatic cancer [96]. Although It is clear that exosomes essential roles in controlling response to therapy, there is a need for more studies and clinical trials so that exosomes can be used as usual monitoring therapy response agents not only for pancreatic cancer but also for other types of cancer.

\section{Conclusions}

Pancreatic cancer is one of the most lethal diseases among solid malignancies. Most patients are diagnosed with advanced or metastatic pancreatic cancer. Also, Pancreatic cancer is resistant to its routine treatments, and pancreatic cancer does not have both successful target therapies or sensitive diagnostic tools. It is essential to continue doing deep researches so that we can find for early diagnosis and establish novel therapeutic targets for pancreatic cancer. Taken together, exosomes play a significant role in intercellular communication. Several studies also confirmed that exosomes can be released by all kinds of cells and are significantly associated with multiple cancers, including pancreatic cancer. Many pieces of research proved that exosomes correlate with biogenesis, progression, metastasis, and tumor immunity in pancreatic cancer; also, exosomes are detectable in different body fluids, and that makes exosomes to be used as pancreatic cancer biomarkers. Besides, exosomes are involved in cell-cell communication, and this makes them potential candidates to be used to produce new therapeutic novels to treat not only pancreatic cancer but also other types of cancer. Although we have attempted to summarize the roles of exosomes in the treatment and diagnosis of pancreatic cancer, it is necessary to conduct in-depth researches and clinical trials so that exosomes can be used as a daily treatment and diagnostic tool for pancreatic cancer in the future. 


\section{Abbreviations}

PC: Pancreatic cancer; EMT: Epithelial-mesenchymal transition; TME: Tumor microenvironment; ESCRT: Endosomal sorting complexes required for transport; MAP 4 K4: Mitogen-Activated Protein Kinase Kinase Kinase 4; MAP 3 K9: Mitogen-Activated Protein Kinase Kinase Kinase Kinase 9; MAPK ERK: Mitogen-activated protein kinase /extracellular-signal-regulated kinase; PTEN/ PI3Ky: Phosphatase and Tensin Homolog / Phosphoinositide 3-Kinase

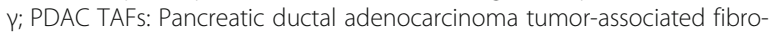
blasts; HMVEC: Human microvascular endothelial cell; BTG2: B cell translocation gene 2; IPMN: Intraductal papillary mucinous neoplasm; TNM: Tumour Node Metastasis; DLC1: Deleted in liver cancer 1; TUG1: Taurine Up-Regulated 1; HMGB1: High Mobility Group Box 1; siRNA: Small interfering RNA; GEMMs: Genetically engineered mouse models; ECM: Excess extracellular matrix; CAFs: Cancer-associated fibroblasts

\section{Acknowledgments}

Not applicable.

\section{Authors' contributions}

ANAG and FW designed and drafted the manuscript. QL J, U Y, X Y, S A, LT $D, Y S W$, and CX W discussed and revised the manuscript. All authors read and approved the final manuscript.

\section{Funding}

This work was supported by the National Natural Science Foundation of China (No.81874040). This work was also supported by a grant from the Key Research and Developmental Program of Shandong Province (2018YFJH0505), and the Taishan Scholars Program (2019GSF108218).

\section{Availability of data and materials}

Not applicable.

\section{Ethics approval and consent to participate}

Not applicable.

\section{Consent for publication}

Not applicable.

\section{Competing interests}

The authors declare that they have no competing interests.

\section{Author details}

${ }^{1}$ Department of Clinical Laboratory, The Second Hospital, Cheeloo College of Medicine, Shandong University, Jinan, Shandong 250033, People's Republic of China. ${ }^{2}$ Department of Clinical Laboratory Diagnostics, School of Medicine, Cheeloo College of Medicine, Shandong University, Jinan, Shandong 250012, People's Republic of China. Institute of Medical Sciences, The Second Hospital, Cheeloo College of Medicine, Shandong University, Jinan, Shandong 250033, People's Republic of China. ${ }^{4}$ Marine College, Shandong University, Weihai 264209, People's Republic of China. ${ }^{5}$ Department of Clinical Laboratory, Qilu Hospital, Cheeloo College of Medicine, Shandong University, Jinan, Shandong 250012, People's Republic of China.

\section{Received: 22 April 2020 Accepted: 12 August 2020}

Published online: 27 August 2020

\section{References}

1. Raphael BJ, Hruban RH, Aguirre AJ. Moffitt RA. Stewart C, et al. Integrated Genomic Characterization of Pancreatic Ductal Adenocarcinoma. Cancer Cell: Yeh JJ; 2017.

2. Siegel RL, Miller KD, Jemal A. Cancer statistics, 2019. CA Cancer J Clin Wiley. 2019:69:7-34.

3. Bray F, Ferlay J, Soerjomataram I. Global Cancer Statistics 2018 : GLOBOCAN Estimates of Incidence and Mortality Worldwide for 36 Cancers in 185 Countries. 2018:394-424.

4. Kaur S, Baine MJ, Jain M, Sasson AR, Batra SK. Early diagnosis of pancreatic cancer: Challenges and new developments. Biomark. Med. NIH Public Access; 2012. p. 597-612.

5. Siegel R, Naishadham D, Jemal A. Cancer statistics, 2013. CA Cancer J Clin American Cancer Society. 2013;63:11-30.
6. Garrido-Laguna I, Hidalgo M. Pancreatic cancer: from state-of-the-art treatments to promising novel therapies. Nat Rev Clin Oncol Nature Publishing Group. 2015;12:319-34.

7. Yuan C, Morales-Oyarvide V, Babic A, Clish CB, Kraft P, Bao Y, et al. Cigarette smoking and pancreatic Cancer survival. J Clin Oncol American Society of Clinical Oncology. 2017;35:1822-8.

8. Schulte A, Pandeya N, Fawcett J, Fritschi L, Klein K, Risch HA, et al. Association between family cancer history and risk of pancreatic cancer. Cancer Epidemiol Elsevier. 2016;45:145-50.

9. Midha S, Chawla S, Garg PK. Modifiable and non-modifiable risk factors for pancreatic cancer: a review. Cancer Lett Elsevier. 2016;381:269-77.

10. Krejs GJ. Pancreatic cancer: epidemiology and risk factors. Dig Dis. 2010.

11. Andersen DK, Korc M, Petersen GM, Eibl G, Li D, Rickels MR, et al. Diabetes, Pancreatogenic diabetes, and pancreatic Cancer. Diabetes American Diabetes Association. 2017:66:1103-10.

12. Pothuraju R, Rachagani S, Junker WM, Chaudhary S, Saraswathi V, Kaur $S$, et al. Pancreatic cancer associated with obesity and diabetes: an alternative approach for its targeting. J Exp Clin Cancer Res. BioMed Central; 2018:37:319.

13. Bethea TN, Kitahara CM, Sonderman J, Patel AV, Harvey C, Knutsen SF, et al. A pooled analysis of body mass index and pancreatic cancer mortality in african americans. Cancer Epidemiol biomarkers Prev. NIH Public Access. 2014;23:2119-25.

14. Matters GL, Cooper TK, McGovern CO, Gilius EL, Liao J, Barth BM, et al. Cholecystokinin mediates progression and metastasis of pancreatic cancer associated with dietary fat. Dig Dis Sci NIH Public Access. 2014;59:1180-91.

15. Mori H. Pancreatic Cancer : pancreatic Cancer : overview. Lancet. 2011;378: 1605-17.

16. Hashimoto D, Arima K, Yokoyama N, Chikamoto A, Taki K, Inoue R, et al. Heterogeneity of KRAS mutations in pancreatic ductal adenocarcinoma. Pancreas. 2016;45:1111-4.

17. Waddell N, Pajic M, Patch A-M, Chang DK, Kassahn KS, Bailey P, et al. Whole genomes redefine the mutational landscape of pancreatic cancer. Nature NIH Public Access. 2015:518:495-501.

18. Hingorani SR, Wang L, Multani AS, Combs C, Deramaudt TB, Hruban RH, et al. Trp53R172H and KrasG12D cooperate to promote chromosomal instability and widely metastatic pancreatic ductal adenocarcinoma in mice. Cancer Cell Elsevier. 2005;7:469-83.

19. Martinez-Useros J, Garcia-Foncillas J. Can Molecular Biomarkers Change the Paradigm of Pancreatic Cancer Prognosis? Biomed Res Int. Hindawi Limited; 2016;2016:4873089.

20. Gopinathan A, Morton JP, Jodrell DI, Sansom OJ. GEMMs as preclinical models for testing pancreatic cancer therapies. Dis Model Mech. 2015;8:1185-200.

21. Bigagli E, Luceri C, Guasti D, Cinci L. Exosomes secreted from human colon cancer cells influence the adhesion of neighboring metastatic cells: Role of microRNA-210. Cancer Biol Ther. Taylor and Francis Inc.; 2016;17:1062-9.

22. Kahlert C, Melo SA, Protopopov A, Tang J, Seth S, Koch O, et al. Identification of doublestranded genomic dna spanning all chromosomes with mutated KRAS and P53 DNA in the serum exosomes of patients with pancreatic cancer. J Biol Chem. 2014.

23. Osterman CID, Lynch JC, Leaf P. Gonda a. Griffiths D, et al. Curcumin modulates pancreatic adenocarcinoma cell-derived exosomal function. PLoS One: Bennit HRF; 2015.

24. Madhavan B, Yue S, Galli U, Rana S, Gross W, Müller M, et al. Combined evaluation of a panel of protein and miRNA serum-exosome biomarkers for pancreatic cancer diagnosis increases sensitivity and specificity. Int J Cancer. 2015.

25. Zöller M. Pancreatic cancer diagnosis by free and exosomal miRNA. World J Gastrointest Pathophysiol. 2013.

26. Ko J. Bhagwat N. Ortiz N, Sahmoud A, Black T, et al. Combining Machine Learning and Nanofluidic Technology to Diagnose Pancreatic Cancer Using Exosomes. ACS Nano: Yee SS; 2017.

27. Kalluri R. The biology and function of exosomes in cancer. J. Clin. Invest. American Society for Clinical Investigation; 2016. p. 1208-1215.

28. Aqil F, Munagala R, Jeyabalan J, Agrawal AK, Gupta R. Exosomes for the enhanced tissue bioavailability and efficacy of Curcumin. AAPS J Springer New York LLC. 2017:19:1691-702.

29. Schneider A. Simons M. Exosomes: Vesicular carriers for intercellular communication in neurodegenerative disorders. Cell Tissue Res. Cell Tissue Res; 2013. p. 33-47.

30. Mathivanan S, Ji H. Simpson RJ. Exosomes: Extracellular organelles important in intercellular communication. J. Proteomics. J Proteomics; 2010. p. 1907-20. 
31. Villarroya-Beltri C, Baixauli F, Gutiérrez-Vázquez C, Sánchez-Madrid F, Mittelbrunn M. Sorting it out: Regulation of exosome loading. Semin. Cancer Biol. Academic Press; 2014. p. 3-13.

32. Keerthikumar S, Chisanga D, Ariyaratne D, Al Saffar H, Anand S, Zhao K, et al. ExoCarta: a web-based compendium of Exosomal cargo. J Mol Biol Academic Press. 2016:428:688-92.

33. Iraci N, Leonardi T, Gessler F, Vega B, Pluchino S. Focus on extracellular vesicles: physiological role and signalling properties of extracellular membrane vesicles. MDPI AG: Int. J. Mol. Sci; 2016.

34. Li W, Li C, Zhou T, Liu X, Liu X, Li X, et al. role of exosomal proteins in cancer diagnosis. Mol. Cancer. BioMed Central Ltd.; 2017.

35. Hannafon BN, Carpenter KJ, Berry WL, Janknecht R, Dooley WC, Ding WQ. Exosome-mediated microRNA signaling from breast cancer cells is altered by the anti-angiogenesis agent docosahexaenoic acid (DHA). Mol Cancer. BioMed Central Ltd.; 2015;14.

36. Li LM, Liu H, Liu XH, Hu H Bin, Liu SM. Clinical significance of exosomal miRNAs and proteins in three human cancers with high mortality in China (Review). Oncol. Lett. Spandidos Publications; 2019. p. 11-22.

37. Muller L, Hong CS, Stolz DB, Watkins SC, Whiteside TL. Isolation of biologically-active exosomes from human plasma. J Immunol Methods Elsevier. 2014;411:55-65.

38. Lu L. Risch HA. Exosomes: Potential for early detection in pancreatic cancer. Futur. Oncol. Future Medicine Ltd.; 2016. p. 1081-90.

39. Kapetanakis NI, Baloche V, Busson P. Tumor exosomal microRNAs thwarting anti-tumor immune responses in nasopharyngeal carcinomas. Ann. Transl. Med: AME Publishing Company; 2017.

40. Mees ST, Mardin WA, Wendel C, Baeumer N, Willscher E, Senninger N, et al. EP300 - a miRNA-regulated metastasis suppressor gene in ductal adenocarcinomas of the pancreas. Int J Cancer. 2010.

41. Li Z, Tao Y, Wang $X$, Jiang P, Li J, Peng M, et al. Tumor-secreted exosomal miR-222 promotes tumor progression via regulating P27 expression and relocalization in pancreatic cancer. Cell Physiol Biochem. 2018.

42. Botla SK, Savant S, Jandaghi P, Bauer AS, Mucke O, Moskalev EA, et al. Early epigenetic downregulation of microRNA-192 expression promotes pancreatic cancer progression. Cancer Res. 2016.

43. Fu Y, Liu X, Chen Q, Liu T, Lu C, Yu J, et al. Downregulated miR-98-5p promotes PDAC proliferation and metastasis by reversely regulating MAP 4K4. J Exp Clin Cancer Res. BioMed Central Ltd.; 2018;37:130.

44. Wang S, Ji J, Song J, Li X, Han S, Lian W, et al. MicroRNA-182 promotes pancreatic cancer cell proliferation and migration by targeting $\beta-\operatorname{TrCP} 2$. Acta Biochim Biophys Sin Shanghai. 2016.

45. Weiss FU, Marques IJ, Woltering JM, Vlecken DH, Aghdassi A, Partecke LI, et al. Retinoic acid receptor antagonists inhibit miR-10a expression and block metastatic behavior of pancreatic Cancer. Gastroenterology. 2009.

46. Wang X, Luo G, Zhang K, Cao J, Huang C, Jiang T, et al. Hypoxic tumorderived exosomal miR-301a mediates M2 macrophage polarization via PTEN/PI3Kg to promote pancreatic cancer metastasis. Cancer Res. American Association for Cancer Research Inc:; 2018;78:4586-98.

47. Kadera BE, Li L, Toste PA, Wu N, Adams C, Dawson DW, et al. MicroRNA-21 in pancreatic ductal adenocarcinoma tumor-associated fibroblasts promotes metastasis. PLoS One. 2013.

48. Diaz-Riascos ZV, Ginesta MM, Fabregat J, Serrano T, Busquets J, Buscail L, et al. Expression and role of MicroRNAs from the miR-200 family in the tumor formation and metastatic propensity of pancreatic Cancer. Mol Ther nucleic acids. Cell Press. 2019;17:491-503.

49. Hu J, Li L, Chen H, Zhang G, Liu H, Kong R, et al. MiR-361-3p regulates ERK1/2-induced EMT via DUSP2 mRNA degradation in pancreatic ductal adenocarcinoma. Cell Death Dis Nature Publishing Group. 2018;9:1-15.

50. Zhu G, Zhou L, Liu H, Shan Y, Zhang X. MicroRNA-224 promotes pancreatic cancer cell proliferation and migration by targeting the TXNIP-mediated HIF1a pathway. Cell Physiol Biochem. 2018.

51. Song M, Sun M, Xia L, Chen W, Yang C. miR-19b-3p promotes human pancreatic cancer Capan-2 cells proliferation by targeting phosphatase and tension homolog. Ann Transl Med. 2019;

52. Shang D, Xie C, Hu J, Tan J, Yuan Y, Liu Z, et al. Pancreatic cancer cellderived exosomal microRNA-27a promotes angiogenesis of human microvascular endothelial cells in pancreatic cancer via BTG2. J Cell Mol Med. 2020.

53. Nuzhat Z, Kinhal V. Sharma S. Joshi V, Salomon C. Tumour-derived exosomes as a signature of pancreatic cancer - liquid biopsies as indicators of tumour progression. Oncotarget: Rice GE; 2017.
54. Carmicheal J, Hayashi C, Huang X, Liu L, Lu Y, Krasnoslobodtsev A, et al. Label-free characterization of exosome via surface enhanced Raman spectroscopy for the early detection of pancreatic cancer. Biol Med: Nanomedicine Nanotechnology; 2019.

55. Kosaka N. Decoding the secret of Cancer by means of extracellular vesicles. J Clin Med. 2016.

56. Hannafon BN, Ding WQ. Intercellular communication by exosome-derived microRNAs in cancer. Int J Mol Sci. 2013.

57. Xu YF, Hannafon BN, Zhao YD, Postier RG, Ding WQ. Plasma exosome miR196a and miR-1246 are potential indicators of localized pancreatic cancer. Oncotarget. 2017.

58. Goto T, Fujiya M, Konishi H, Sasajima J, Fujibayashi S, Hayashi A, et al. An elevated expression of serum exosomal microRNA-191, - 21, -451a of pancreatic neoplasm is considered to be efficient diagnostic marker. BMC Cancer. 2018.

59. Abue M, Yokoyama M, Shibuya R, Tamai K, Yamaguchi K, Sato I, et al. Circulating miR-483-3p and miR-21 is highly expressed in plasma of pancreatic cancer. Int J Oncol Spandidos Publications. 2015;46:539-47.

60. Engle DD, Tiriac H, Rivera KD, Pommier A, Whalen S, Oni TE, et al. The glycan CA19-9 promotes pancreatitis and pancreatic cancer in mice. Science (80- ). 2019;

61. Kondo N, Murakami Y, Uemura K, Hayashidani Y, Sudo T, Hashimoto Y, et al. Prognostic impact of perioperative serum CA 19-9 levels in patients with resectable pancreatic cancer. Ann Surg Oncol. 2010.

62. Liu J, Gao J, Du Y, Li Z, Ren Y, Gu J, et al. combination of plasma microRNAs with serum CA19-9 for early detection of pancreatic cancer. Int J Cancer. 2012;

63. Kawamura S, linuma H, Wada K, Takahashi K, Minezaki S, Kainuma M, et al. Exosome-encapsulated microRNA-4525, microRNA-451a and microRNA-21 in portal vein blood is a high-sensitive liquid biomarker for the selection of high-risk pancreatic ductal adenocarcinoma patients. J Hepatobiliary Pancreat Sci. 2019.

64. Kimura H, Yamamoto H, Harada T, Fumoto K, Osugi Y, Sada R, et al. CKAP4, a DKK1 receptor, is a biomarker in exosomes derived from pancreatic cancer and a molecular target for therapy. Clin Cancer Res. 2019.

65. Nuzhat Z, Palma C, Rice GE, Joshi V, Salomon C. Exosomes in pancreatic juice as valuable source of biomarkers for early diagnosis of pancreatic cancer. Transl Cancer Res. 2017:6:S1339-51.

66. Machida T, Tomofuji T, Maruyama T, Yoneda T, Ekuni D, Azuma T, et al. MIR 1246 and MIR-4644 in salivary exosome as potential biomarkers for pancreatobiliary tract cancer. Oncol Rep. 2016.

67. Wang J, Chen J, Chang P, LeBlanc A, Li D. Abbruzzesse JL, et al. Cancer Prev Res: MicroRNAs in plasma of pancreatic ductal adenocarcinoma patients as novel blood-based biomarkers of disease; 2009.

68. Pu X, Ding G, Wu M, Zhou S, Jia S, Cao L. Elevated expression of exosomal microRNA-21 as a potential biomarker for the early diagnosis of pancreatic cancer using a tethered cationic lipoplex nanoparticle biochip. Oncol Lett. 2020.

69. Que R, Ding G, Chen J, Cao L. Analysis of serum exosomal microRNAs and clinicopathologic features of patients with pancreatic adenocarcinoma. World J Surg Oncol. 2013.

70. Joshi GK, Deitz-McElyea S, Liyanage T, Lawrence K, Mali S, Sardar R, et al. Labelfree Nanoplasmonic-based short noncoding RNA sensing at Attomolar concentrations allows for quantitative and highly specific assay of MicroRNA10b in biological fluids and circulating Exosomes. ACS Nano. 2015.

71. Taller D, Richards K, Slouka Z, Senapati S, Hill R. Go DB, et al. Lab Chip: Onchip surface acoustic wave lysis and ion-exchange nanomembrane detection of exosomal RNA for pancreatic cancer study and diagnosis; 2015.

72. Lai X, Wang M, McElyea SD, Sherman S, House M, Korc M. A microRNA signature in circulating exosomes is superior to exosomal glypican-1 levels for diagnosing pancreatic cancer. Cancer Lett. 2017.

73. Langevin SM, Kuhnell D, Zhang X, Wise-Draper TM, Casper KA. Abstract 26: Exosomal microRNA as salivary biomarkers of head and neck squamous cell carcinoma; 2017.

74. Puik JR, Meijer LL, Large TY Le, Heger M, Dijk F, Funel N, et al. Abstract 493: circulating biliary tract microRNA signature discriminates cholangiocarcinoma from pancreatic cancer. 2018.

75. Pascucci $L$, Coccè V, Bonomi A, Ami D, Ceccarelli P, Ciusani E, et al. Paclitaxel is incorporated by mesenchymal stromal cells and released in exosomes that inhibit in vitro tumor growth: a new approach for drug delivery. J Control Release. 2014.

76. Aspe JR, Osterman CJD, Jutzy JMS, Deshields S, Whang S, Wall NR. Enhancement of gemcitabine sensitivity in pancreatic adenocarcinoma by novel exosomemediated delivery of the Survivin-T34A mutant. J Extracell Vesicles. 2014. 
77. Xia J, Cao T, Ma C, Shi Y, Sun Y, Wang ZP, et al. miR-7 Suppresses Tumor Progression by Directly Targeting MAP 3 K9 in Pancreatic Cancer. Mol Ther Nucleic Acids. 2018;

78. Zhou B, Sun C, Hu X, Zhan H, Zou H, Feng Y, et al. MicroRNA-195 suppresses the progression of pancreatic Cancer by targeting DCLK1. Cell Physiol Biochem. 2018.

79. Takahashi K, Ehata S, Koinuma D, Morishita Y, Soda M. Mano H, et al. Oncogene: Pancreatic tumor microenvironment confers highly malignant properties on pancreatic cancer cells; 2018.

80. Xu K, Zhang L. Inhibition of TUG1/miRNA-299-3p Axis represses pancreatic Cancer malignant progression via suppression of the Notch1 pathway. Springer New York LLC: Dig Dis Sci; 2019.

81. Guo S, Fesler A, Huang W, Wang Y, Yang J, Wang X, et al. Functional significance and therapeutic potential of miR-15a mimic in pancreatic ductal adenocarcinoma. Mol Ther - Nucleic Acids. 2020.

82. Xiong J, Wang D, Wei A, Ke N, Wang Y, Tang J, et al. MicroRNA-410-3p attenuates gemcitabine resistance in pancreatic ductal adenocarcinoma by inhibiting HMGB1-mediated autophagy. Oncotarget Impact Journals LLC. 2017:8:107500-12.

83. Kamisawa T, Wood LD, Itoi T. Takaori K. Lancet: Pancreatic cancer; 2016.

84. Cheng H, Fan K, Luo G, Fan Z, Yang C, Huang Q, et al. KrasG12D mutation contributes to regulatory $T$ cell conversion through activation of the MEK/ERK pathway in pancreatic cancer. Cancer Lett Elsevier Ireland Ltd. 2019;446:103-11.

85. Kamerkar S, Lebleu VS, Sugimoto H. Yang S. Melo SA, et al. Exosomes facilitate therapeutic targeting of oncogenic KRAS in pancreatic cancer. Nature: Ruivo CF; 2017.

86. Korc M. McElyea SD. Pancreat Cancer: Cancer exosomes for early pancreatic cancer diagnosis and role in metastasis; 2018.

87. Whiteside TL. Tumor-derived Exosomes and their role in Cancer progression. Adv Clin Chem. 2016.

88. Kim H, Kim DW, Cho JY. Exploring the key communicator role of exosomes in cancer microenvironment through proteomics. Proteome Sci. 2019.

89. Richards KE, Zeleniak AE, Fishel ML, Wu J, Littlepage LE, Hill R. Cancerassociated fibroblast exosomes regulate survival and proliferation of pancreatic cancer cells. Oncogene. 2017:

90. Stefanius K, Servage K, Santos M de S, Gray HF, Toombs JE, Chimalapati S, et al. Human pancreatic cancer cell exosomes, but not human normal cell exosomes, act as an initiator in cell transformation. Elife. 2019;

91. Yin Z, Ma T, Huang B, Lin L, Zhou Y, Yan J, et al. Macrophage-derived exosomal microRNA-501-3p promotes progression of pancreatic ductal adenocarcinoma through the TGFBR3-mediated TGF- $\beta$ signaling pathway. J Exp Clin Cancer Res. 2019.

92. Ballehaninna UK, Chamberlain RS. Biomarkers for pancreatic cancer: promising new markers and options beyond CA 19-9. Tumor Biol. 2013.

93. Melo SA, Luecke LB, Kahlert C, Fernandez AF, Gammon ST, Kaye J, et al. Glypican-1 identifies cancer exosomes and detects early pancreatic cancer. Nature. 2015.

94. Adamczyk KA, Klein-Scory S, Tehrani MM, Warnken U, Schmiegel W Schnölzer M, et al. Characterization of soluble and exosomal forms of the EGFR released from pancreatic cancer cells. Life Sci. 2011.

95. Tian X, Shivapurkar N, Wu Z, Hwang JJ, Pishvaian MJ, Weiner LM, et al. Circulating microRNA profile predicts disease progression in patients receiving second-line treatment of lapatinib and capecitabine for metastatic pancreatic cancer. Oncol Lett. 2016;.

96. Miyamae M, Komatsu S, Ichikawa D, Kawaguchi T, Hirajima S, Okajima W, et al. Plasma microRNA profiles: identification of miR-744 as a novel diagnostic and prognostic biomarker in pancreatic cancer. Br J Cancer. 2015.

\section{Publisher's Note}

Springer Nature remains neutral with regard to jurisdictional claims in published maps and institutional affiliations.

Ready to submit your research? Choose BMC and benefit from:

- fast, convenient online submission

- thorough peer review by experienced researchers in your field

- rapid publication on acceptance

- support for research data, including large and complex data types

- gold Open Access which fosters wider collaboration and increased citations

- maximum visibility for your research: over $100 \mathrm{M}$ website views per year

At $\mathrm{BMC}$, research is always in progress.

Learn more biomedcentral.com/submissions 